\title{
Management of guttate psoriasis in patients with associated streptococcal infection
}

\author{
This article was published in the following Dove Press journal: \\ Psoriasis: Targets and Therapy \\ 19 November 2012 \\ Number of times this article has been viewed
}

\author{
Özlem Karabudak Abuaf \\ Bilal Dogan \\ Department of Dermatology, \\ GATA Haydarpasa Teaching Hospital, \\ Istanbul, Turkey
}

\begin{abstract}
Psoriasis is a T cell-mediated inflammatory skin disease. It can be provoked or exacerbated by environmental factors, particularly medications and infections. Guttate psoriasis is a distinctive acute form of psoriasis that generally occurs in children and young adults. The association between guttate psoriasis and Streptococcus pyogenes is well established in medical literature; however, the exact mechanism can only be theorized. Treatment guidelines are not established, and it is unclear how necessary antibiotics are for acute state guttate psoriasis. Many dermatologists have recommended using antibiotic therapy or tonsillectomy, especially for patients with recurrent streptococcal infections. This paper briefly summarizes the possible mechanisms of pathogenesis and the recent research results on this topic and examines under what conditions a curative treatment of streptococcal infection by tonsillectomy or antibiotic treatment may benefit psoriasis patients.
\end{abstract}

Keywords: guttate, psoriasis, treatment, Streptococcus pyogenes

\section{An evaluation of the role of streptococcal infection in the management of the guttate psoriasis The role of environmental factors in the pathogenesis of psoriasis}

Psoriasis is a T-cell-mediated inflammatory skin disease. Environmental and genetic factors play important roles in the appearance of the disease. Psoriasis has a genetically heterogeneous nature. Currently, 20 different genes associated with the disease have been defined. Among these, the strongest association is with human leukocyte antigen Cw0602. In Cw0602-positive patients, the disease has a more aggressive course and can be easily triggered by environmental factors. In nearly one-third of all cases, environmental factors are known to be influential in the appearance or recurrence of the disease. ${ }^{1,2}$ These factors are quite diverse, consisting primarily of medications (such as lithium, $\beta$-blockers, angiotensin-converting enzyme inhibitors, antimalarial agents, nonsteroidal anti-inflammatory drugs, carbamazepine, tetracycline, and interferon- $\alpha / \beta$ ) and infections (from microorganisms such as Staphylococcus aureus, Streptococcus pyogenes, malassezia furfur, Candida albicans, and human papilloma virus type 5, human immunodeficiency virus), as well as physical/chemical traumas, stress, hypocalcemia, alcohol consumption, and smoking. . $^{1,3}$

Guttate psoriasis is a distinctive acute form of psoriasis in which a shower of small plaques appears in widespread distribution over the body. It characteristically occurs in children and young adults. Up to $33 \%$ of the patients with guttate psoriasis can progress
Correspondence: Özlem Karabudak Abuaf GATA Haydarpasa Teaching Hospital, Tibbiye Cad 81327 Kadıkoy, Istanbul, Turkey Tel +90216542 2000 Ext 3703

Fax +902126543167

Email okabuaf@gata.edu.tr 
to the chronic plaque form in 10 years. Guttate psoriasis is closely associated with preceding streptococcal infections, usually in the form of tonsillopharyngitis. In 56\%-100\% of patients with guttate psoriasis, there is a clinically proven case of streptococcal infection. ${ }^{5}$ Although the positive relationship between guttate psoriasis and streptococcal infection has been demonstrated, the exact mechanism can only be theorized.

\section{Psoriasis and streptococci}

Streptococci are facultative anerobic microorganisms that are Gram-positive, catalase-negative, nonmotile, and nonsporing. Streptococcus was first described by Billroth in $1874 .{ }^{6}$ Different classifications have been made based on its various features. In 1903, Brown and Schottmueller classified streptococci by examining the $\beta$-, $\alpha$-, and $\gamma$-hemolysis zones they produce on blood agar plates (5\% sheep blood agar). ${ }^{6}$ As $S$. pyogenes produced a total hemolytic zone, it was evaluated as being beta hemolytic. Lancefield classification emphasized their antigenic properties and was based on the serological differences of cellwall polysaccharides. ${ }^{6}$ Serotypes range from A to T. Group A streptococci, also known as $S$. pyogenes, are divided into different serotypes based on M-, R-, and T-surface antigens. ${ }^{6}$

$S$. pyogenes infections have a distinct relationship with the activation of guttate psoriasis. ${ }^{7}$ This relationship was first described by Winfield ${ }^{8}$ in 1916 . In 1955, Norrlind pointed out the presence of a history of a streptococcal upper respiratory infection 1-2 weeks prior to the appearance of the skin lesions in two-thirds of guttate psoriasis cases. ${ }^{9}$ During different studies following this observation, both the presence of streptococcal microorganisms in the throat cultures of these patients as well as the positivity of antistreptococcal antibodies in their serums were shown. Although most guttate psoriasis patients were identified as having Lancefield Group A streptococci in their tonsils, some also harbored Group $\mathrm{C}$ and $\mathrm{G} .{ }^{10,11}$ In the tissues, like tonsils, that streptococci tend to infect, the microorganisms penetrate into eukaryotic cells, like squamous epithelium or macrophages, resulting in persistent carriage or recurrent infections. Pathological examinations of these tissues performed after tonsillectomies confirmed that streptococci could persist in tonsils and pharynges and could eventually colonize them. ${ }^{12}$ The microorganisms' ability to penetrate and colonize is important with regard to their role in triggering psoriasis.

\section{Internalization of streptococci and the transforming growth factor- $\beta$ (TGF- $\beta$ )/ fibronectin $/ \alpha 5 \beta$ I integrin pathway}

Streptococci are intracellular microorganisms. Streptococcal surface proteins $\mathrm{M}, \mathrm{Sfd} 1, \mathrm{~F} 1$, and other proteins with similar structures play roles in the tissue internalization of streptococci. These proteins all bind to arginine-glycineaspartic acid, which has a fibronectin motif. Arginineglycine-aspartic acid is an important integrin responsible for signalization in the extracellular matrix. The streptococci fibronectin complex binds to another integrin, $\alpha 5 \beta 1$, located on the host cell wall. The clustering of $\alpha 5 \beta 1$ that ensues triggers the internalization on the cell wall and endolytic pathway. ${ }^{13,14}$

The TGF- $\beta$ family contains most of the extracellular growth factors, and it includes several polypeptide growth factors of a structure similar to the extracellular growth factors. TGF- $\beta$ has the ability to regulate cellular processes like cellular proliferation, differentiation, motility, adhesion, and death. ${ }^{15}$ Furthermore, TGF- $\beta$ also promotes an increase in the expression of $\alpha 5 \beta 1$ and the clustering of fibronectin. In one study, human tonsil fibroblasts were stimulated by $\beta$-hemolytic streptococci, resulting in an increase in TGF- $\beta$ production; this situation strengthened $\alpha 5 \beta 1$ expression, eventually leading to a further increase in the internalization of the bacterium into the epithelial tissue. ${ }^{16}$

\section{Psoriasis and the TGF- $\beta$ /fibronectin/ $\alpha 5 \beta$ I integrin pathway}

Keratinocyte growth is regulated by the fibronectin receptor $\alpha 5 \beta 1$, which also stimulates hyperproliferation. $\alpha 5 \beta 1$ is poorly expressed in normal skin. By contrast, fibronectin and $\alpha 5 \beta 1$ are overexpressed in involved and uninvolved psoriatic skin keratinocytes. Fibronectin increases cell cycle entry among uninvolved psoriatic skin cells in the proximity of a psoriatic lesion but not in normal skin. As a result, psoriatic keratinocytes have disturbed integrin function in the cutaneous area, stimulate cell cycle entry, and trigger hyperproliferation without an increase in adhesion. This pathway is important for psoriasis and the internalization of streptococci. ${ }^{14,17}$

\section{T cells, psoriasis, and streptococcal infections}

The Th17 cell and its related cytokine network play a role in TGF- $\beta$ production and mucosal defense during bacterial infections. Streptococcal infections lead to production of interleukin 6 (IL-6) by the host. The presence of IL-6 and TGF- $\beta$ results in a differentiation of Th17 at that location, and it mobilizes the Th17 network primarily with IL-17 and IL-22. IL-17 and IL-22 promote the production of antimicrobial peptides locally. Furthermore, the presence of IL- 6 and TGF- $\beta$ ensures the migration of neutrophils and 
mononuclear cells to the region. With the strong production of myeloperoxidase and elastase by neutrophils, extracellular pathogens are killed. However, in instances where the pathogen is intracellular, neutrophils are ineffective. Similarly, M protein causes a strong immunostimulation in the host and is recognized by toll-like receptors (TLR). Stimulation of TLRs mobilizes proinflammatory cytokines like TNF, IL-6, and IL-1 $\beta$, as well as inflammatory cells like neutrophils and macrophages. Recently, the interaction of M protein with TLR-2 was shown to stimulate the secretions of TNF- $\alpha$, IL- 6 , and IL-1 $\beta$ from the monocytes. ${ }^{18,19}$

CD4+ and CD8+ cells isolated from psoriatic plaques were shown to respond to streptococcal antigens. Group A streptococcal wall antigens are primarily made up of peptidoglycans (PG). In one study, CD4+ T-cell lines isolated from psoriatic and nonpsoriatic sites were examined, and $T$ cells located on the psoriatic dermal sites were shown to respond to streptococcal peptidoglycans by proliferating and secreting interferon- $\gamma$. It was suggested that peptidoglycans could lead to T-cell activation during psoriasis. ${ }^{20,21}$

\section{Guttate psoriasis and streptococci as superantigens}

Superantigens can directly bind to major histocompatibility complex class 2 molecules without being processed. Compared to conventional peptide antigens, $\mathrm{T}$ lymphocytes have been shown to be more easily activated. This binding is realized when a V $\beta 2$ region is present within the T cell. ${ }^{20,22}$ Leung et $\mathrm{al}^{23}$ reported that streptococcal isolates from throat cultures of guttate psoriasis patients secreted streptococcus pyogenes exotoxin $C$, which triggered expansion of $\mathrm{V} \beta 2$ bearing $\mathrm{T}$ cells. Leung et $\mathrm{al}^{23}$ and Lewis et $\mathrm{al}^{24}$ also showed a selective accumulation of $\mathrm{V} \beta 2+\mathrm{T}$ cells on lesional and perilesional skin of the patients.

Another possible mechanism through which streptococci can exacerbate psoriasis is molecular mimicking. Molecular mimicking can be described as infectious antigens having amino acid sequences similar or equivalent to endogenous peptides. Some studies show that peptides of streptococcal $\mathrm{M}$ protein and those of keratin 1 contain the same amino acid sequences resulting in cross-reactive $\mathrm{T}$ cell response. ${ }^{25-27}$

Tonsillitis and pharyngitis are the main infections associated with psoriasis. The infections are either latent or chronic. Moreover, perianal streptococcal dermatitis and vulvovaginitis/balanoposthitis infections mostly seen during childhood can induce psoriasis. For this reason, in acute exacerbations of guttate psoriasis, bacterial smears should be obtained from the patients and cultured. Serological studies can also be performed primarily using antibodies against streptolysin, a streptococcal exotoxin. Among these, the most commonly used is antistreptolysin $\mathrm{O} .{ }^{28-30}$

\section{Treatment for psoriatic patients with streptococcal carriage, psoriasis, and tonsillectomy}

The relationship between streptococcal infections and guttate psoriasis brings forward the question of how treatment for streptococcal infections could affect the course of psoriasis over time. In cases of psoriasis where there is a chronic streptococcal carrier state or where there is a link with acute tonsillitis, there are studies and case presentations showing that tonsillectomy could be beneficial, although these are limited in number. In most studies, guttate psoriasis cases were evaluated together with chronic plaque psoriasis. They also evaluated the results of tonsillectomies performed on patients with other forms of psoriasis.

Nyfors et al examined a group of psoriasis patients between the ages of 4-33 years and consisting of 18 men and 56 women for 5 years following tonsillectomy. Of those examined, $32 \%$ were cleared of infection while $39 \%$ showed improvement. The authors recommended that tonsillectomy could be beneficial. ${ }^{31}$ Hone et al conducted a prospective study of 13 patients with streptococcal carriage and concluded that tonsillectomy was beneficial, especially for cases of guttate psoriasis; throughout the 26 months of follow-up, five out of six cases of guttate psoriasis remained in remission. ${ }^{32}$ Kataura and Tsubota performed a study in 1996 showing that in a group with tonsil-related diseases (palmoplantar pustulosis, psoriasis vulgaris, rheumatoid arthritis, and sternocostoclavicular hyperostosis), of 35 patients with psoriasis, $48.6 \%$ were in remission following tonsillectomy. ${ }^{33}$ In the same study, the best results were for patients with palmoplantar pustulosis, with a remission rate of $88.1 \%$ in a group of 289 patients. Ozawa et al studied 385 patients with generalized pustular psoriasis, and $16.7 \%$ of the cases in this study benefited from tonsillectomy. ${ }^{34}$ McMillin et al studied two pediatric cases of guttate psoriasis. They followed-up their patients for 16 months after tonsillectormy and have not reported any exacerbation. They suggested that tonsillectomy was a good treatment alternative for patients with streptococcal carriage..$^{35}$ Diluvio et al performed tonsillectomies on three patients with streptococcal-induced psoriasis. Following the operations, tonsil tissues were analyzed using T-cell receptor analysis; lymphocytes expressing cutaneous lymphocytesassociated Ag were found to be dominant. Following the tonsillectomies, psoriasis lesions regressed. Diluvio et al suggested that the chronic streptococcal immune stimulus 
within the tonsils could act as a source for pathogenic T cells in poststreptococcal disorders. ${ }^{36}$

Cases in which patients did not benefit from tonsillectomy or experienced recurrences following tonsillectomy were considered to be to the result of colonization of streptococci in other lymphatic tissue. ${ }^{37}$

A limited number of uncontrolled studies and case presentations have demonstrated that psoriasis patients with streptococcal carriage could benefit from tonsillectomies. Larger randomized controlled studies with higher levels of evidence are needed.

\section{Psoriasis and antistreptococcal treatments}

Antibiotics are given to patients with streptococcal carriage for treatment or prevention purposes; however, studies of these groups are small-scale. In these studies, treatments had a mean duration of 10-14 days, and they generally made use of penicillin or macrolide antibiotics (erythromycin, roxithromycin, or clarithromycin) either by themselves or in combination with rifampicin.

Rosenberg et al studied nine patients with streptococcal carriage (five with guttate psoriasis, four with chronic plaque psoriasis); these patients received $250 \mathrm{mg}$ penicillin or erythromycin for 10-14 days. During the last 5 days, rifampin was added to the treatment. By the end of the treatment, all patients either achieved complete clearing or near-complete clearing of psoriatic lesions. However, this study did not detail the clinical and laboratory characteristics of the patients. ${ }^{38}$ In a study by Vincent et al, 20 psoriasis patients with streptococcal carriage ( 7 male and 13 female) between the ages of 12-77 years were randomly divided into two groups. One group was given penicillin or erythromycin for 14 days with the addition of a placebo during the last 5 days. The other group received the same medication with rifampin added during the last 5 days. None of the cases experienced regression of their psoriatic lesions. Based on these findings, the authors did not support the use of antibiotics to prevent or to treat streptococci-associated psoriasis. ${ }^{39}$ Saxena and Dogra performed an uncontrolled study on 30 psoriasis patients in 2005. The patients received benzathine penicillin. During a treatment period of 2 years, the patients' Psoriasis Area and Severity Index (PASI) scores started regressing from 12 weeks onwards. ${ }^{40}$ The authors stated that using long-term benzathine penicillin could be effective in treating psoriasis.

Komine and Tamaki had 17 patients (12 male, 5 female) between ages of 16-79 years. For one month, the patients received $800 \mathrm{mg} /$ day erythromycin, $300 \mathrm{mg} /$ day roxithromycin, or $400 \mathrm{mg} /$ day clarithromycin. None of the patients achieved complete clearing or worsening of their lesions, but $82.4 \%$ experienced improvement. PASI scores regressed from 22.8 to 13.7 . Itching decreased in nearly $54 \%$ of the patients. The authors suggested that macrolides could be used as adjunctive therapies for psoriasis. ${ }^{41}$

Polat et al had 60 patients with psoriasis. Of these, 36 received erythromycin $1000 \mathrm{mg}$ /day for 4 weeks, and 24 received only topical corticosteroids. At the end of the study, the group using antibiotics had better PASI scores, and the authors suggested that macrolides could have a place in the treatment of psoriasis. ${ }^{42}$ Similarly, in a randomized placebo-controlled study by Dogan et al, 43 guttate psoriasis patients were divided into three groups. Group A $(n=15)$ was the untreated group, Group B $(n=14)$ was treated with $1000 \mathrm{mg} /$ day erythromycin for 14 days, and Group C $(\mathrm{n}=14)$ was treated with 50,000 IU/kg/day phenoxymethylpenicillin for 14 days. There was no statistically significant difference between the treatment and control groups during the time of treatment or for the following 6 weeks. $^{5}$ Saxena and Dogra performed another study in 2010 and evaluated the results of long-term azithromycin treatment. At the end of 48 weeks, $60 \%$ of the patients showed excellent improvement, $20 \%$ showed good improvement, and $13.33 \%$ showed mild improvement. ${ }^{43}$

Despite the fact that the studies yielded contradicting results, antibiotics were generally effective in open uncontrolled studies while they were ineffective in controlled studies.

Long-term antibiotic treatment seems to be more effective in preventing psoriatic relapse. It is unclear why short-term antibiotic treatment is not effective in psoriasis treatment. In such patients, recurrent streptococcal infections were shown to be caused by the same strains. ${ }^{44}$ It is possible that, in treatment models of 10-14 days, streptococci with intracellular localization that had penetrated into the tissue could resist treatment. The genetic tendency of the patient is thought to be of importance in this intracellular persistence. In conclusion, the number of existing studies is limited and they have a low level of evidence. Their results differ from each other. This is why the use of antibiotics for psoriasis is still a controversial issue. Studies with large series and higher levels of evidence are needed in this field.

\section{Conclusion}

Although the role of streptococcus in the etiopathogenesis of psoriasis has been better understood over time, the effect of 
antistreptococcal treatment on psoriasis is quite controversial because of the low number of studies and because most of those studies were uncontrolled.

Short-term antibiotic treatment is not effective in cases of acute guttate psoriasis. However, long-term antibiotic treatment seems to be more effective in controlling psoriatic relapse. This might be due to the elimination of antigenic stimulation caused by carried microorganisms.

In patients with acute guttate psoriasis, if the presence of a streptococcal infection has been proven clinically or if a carriage has been identified based on laboratory results, antibiotics can be added to conventional psoriasis treatment. Attention should be paid to choosing antibiotics with intracellular effects. If there is no history of an infectious episode like pharyngitis, or if there is no growth in the culture, antibiotic treatment seems to be unnecessary due to the lack of evidence supporting its benefits. For patients who experience recurrent throat infections or streptococcal carriage, in whom the correlation of such episodes with the exacerbation of psoriasis has been shown, or in those who are unresponsive to antibiotic treatment, a tonsillectomy can be performed if the patient has hypertrophic tonsils. It should be noted that tonsillectomy was shown to be effective only in uncontrolled studies.

Overall, more well-designed, randomized, placebocontrolled studies are needed in this field.

\section{Disclosure}

The authors report no conflicts of interest in this work.

\section{References}

1. Türsen Ü. The etiology of psoriasis. Dermatoz. 2010;1(2):91-108.

2. Oka A, Mabuchi T, Ozawa A, Inoko H. Current understanding of human genetics and genetic analysis of psoriasis. J Dermatol. 2012;39(3): 231-241.

3. Fry L, Baker BS. Triggering psoriasis: the role of infections and medications. Clin Dermatol. 2007;25(6):606-615.

4. Basavaraj KH, Ashok NM, Rashmi R, Praveen TK. The role of drugs in the induction and/or exacerbation of psoriasis. Int J Dermatol. 2010; 49(12):1351-1361.

5. Dogan B, Karabudak O, Harmanyeri Y. Antistreptococcal treatment of guttate psoriasis: a controlled study. Int J Dermatol. 2008;47(9): 950-952.

6. Kilians M. Streptococcus and lactobacillus. In: Borriello SP, Murray PR, Funke G, editors. Topley and Wilson's Microbiology and Microbial Ínfections. London: Hodder Arnold; 2005:853-857.

7. Bos JD, de Rie MA, Teunissen MB, Piskin G. Psoriasis: dysregulation of innate immunity. Br J Dermatol. 2005;152(6):1098-1107.

8. Winfield JM. Psoriasis as sequel to acute inflammation of the tonsils: a clinical note. J Cutan Dis. 1916;34(6):441-443.

9. Norrlind R. The significance of infections in the origination of psoriasis. Acta Rheumatol Scand. 1955;1(2):135-144.

10. Wilson AG, Clark I, Heard SR, Munro DD, Kirby JD. Immunoblotting of streptococcal antigens in guttate psoriasis. Br J Dermatol. 1993; 128(2):151-158.
11. Gudjonsson JE, Thorarinsson AM, Sigurgeirsson B, Kristinsson KG, Valdimarsson H. Streptococcal throat infections and exacerbation of chronic plaque psoriasis: a prospective study. Br J Dermatol. 2003; 149(3):530-534.

12. Park HS, Francis KP, Yu J, Cleary PP. Membranous cells in nasal-associated lymphoid tissue: a portal of entry for the respiratory mucosal pathogen group A streptococcus. J Immunol. 2003;171(5): 2532-2537.

13. McFadden JP, Baker BS, Powles AV, Fry L. Psoriasis and extra domain A fibronectin loops. Br J Dermatol. 2010;163(1):5-11.

14. McFadden JP, Baker BS, Powles AV, Fry L. Psoriasis and streptococci: the natural selection of psoriasis revisited. Br J Dermatol. 2009;160(5): 929-937.

15. Soyoz M, Ozçelik N. TGF- $\beta$ (Transforming Growth Factor- $\beta$ ) ve Sinyal İletimi. Turkiye Klinikleri J Med Sci. 2007;27:426-433.

16. Wang B, Li S, Southern PJ, Cleary PP. Streptococcal modulation of cellular invasion via TGF-beta1 signaling. Proc Natl Acad Sci U S A. 2006;103(7):2380-2385.

17. Bata-Csorgo Z, Cooper KD, Ting KM, Voorhees JJ, Hammerberg C. Fibronectin and alpha5 integrin regulate keratinocyte cell cycling. A mechanism for increased fibronectin potentiation of $\mathrm{T}$ cell lymphokine-driven keratinocyte hyperproliferation in psoriasis. J Clin Invest. 1998; 101(7):1509-1518.

18. Aujla SJ, Dubin PJ, Kolls JK. Th17 cells and mucosal host defense. Semin Immunol. 2007;19(6):377-382.

19. Korn T, Oukka M, Kuchroo V, Bettelli E. Th17 cells: effector T cells with inflammatory properties. Semin Immunol. 2007;19(6): $362-371$.

20. Leung DY, Gately M, Trumble A, Ferguson-Darnell B, Schlievert PM, Picker LJ. Bacterial superantigens induce $\mathrm{T}$ cell expression of the skin-selective homing receptor, the cutaneous lymphocyte-associated antigen, via stimulation of interleukin 12 production. J Exp Med. 1995; 181(2):747-753.

21. Baker BS, Laman JD, Powles A, et al. Peptidoglycan and peptidoglycanspecific Th1 cells in psoriatic skin lesions. Pathol. 2006;209(2): 174-181.

22. Macias ES, Pereira FA, Rietkerk W, Safai B. Superantigens in dermatology. J Am Acad Dermatol. 2011;64(3):455-472.

23. Leung DY, Travers JB, Giorno R, et al. Evidence for a streptococcal superantigen-driven process in acute guttate psoriasis. J Clin Invest. 1995;96(5):2106-2112.

24. Lewis HM, Baker BS, Bokth S, et al. Restricted T-cell receptor V beta gene usage in the skin of patients with guttate and chronic plaque psoriasis. Br J Dermatol. 1993;129(5):514-520.

25. McFadden J, Valdimarsson H, Fry L. Cross-reactivity between streptococcal M surface antigen and human skin. Br J Dermatol. 1991;125(5):443-447.

26. Valdimarsson H, Sigmundsdóttir H, Jónsdóttir I. Is psoriasis induced by streptococcal superantigens and maintained by M-protein-specific T cells that cross-react with keratin? Clin Exp Immunol. 1997; 107 Suppl 1:21-24.

27. Valdimarsson H, Baker BS, Jónsdóttir I, Powles A, Fry L. Psoriasis: a T-cell-mediated autoimmune disease induced by streptococcal superantigens? Immunol Today. 1995;16(3):145-149.

28. Ledoux M, Chazerain V, Saiag P, Mahé E. Streptococcal perianal dermatitis and guttate psoriasis. Ann Dermatol Venereol. 2009;136(1): $37-41$.

29. Krishnamurthy K, Walker A, Gropper CA, Hoffman C. To treat or not to treat? Management of guttate psoriasis and pityriasis rosea in patients with evidence of group A streptococcal infection. J Drugs Dermatol. 2010;9(3):241-250.

30. Geerts I, De Vos N, Frans J, Mewis A. The clinical-diagnostic role of antistreptolysin O antibodies. Acta Clin Belg. 2011;66(6): $410-415$.

31. Nyfors A, Rasmussen PA, Lemholt K, Eriksen B. Improvement of refractory psoriasis vulgaris after tonsillectomy. Dermatologica. 1975; 151(4):216-222. 
32. Hone SW, Donnelly MJ, Powell F, Blayney AW. Clearance of recalcitrant psoriasis after tonsillectomy. Clin Otolaryngol Allied Sci. 1996;21(6):546-547.

33. Kataura A, Tsubota H. Clinical analyses of focus tonsil and related diseases in Japan. Acta Otolaryngol Suppl. 1996;523:161-164.

34. Ozawa A, Ohkido M, Haruki Y, et al. Treatments of generalized pustular psoriasis: a multicenter study in Japan. J Dermatol. 1999;26(3): 141-149.

35. McMillin BD, Maddern BR, Graham WR. A role for tonsillectomy in the treatment of psoriasis? Ear Nose Throat J. 1999;78(3): $155-158$.

36. Diluvio L, Vollmer S, Besgen P, Ellwart JW, Chimenti S, Prinz JC. Identical TCR beta-chain rearrangements in streptococcal angina and skin lesions of patients with psoriasis vulgaris. J Immunol. 2006; 176(11):7104-7111.

37. Prinz JC. The role of streptococci in psoriasis. Hautarzt. 2009;60(2): 109-115.

38. Rosenberg EW, Noah PW, Zanolli MD, Skinner RB Jr, Bond MJ, Crutcher N. Use of rifampin with penicillin and erythromycin in the treatment of psoriasis. Preliminary report. JAm Acad Dermatol. 1986; 14(5 Pt 1):761-764.
39. Vincent F, Ross JB, Dalton M, Wort AJ. A therapeutic trial of the use of penicillin $\mathrm{V}$ or erythromycin with or without rifampin in the treatment of psoriasis. J Am Acad Dermatol. 1992;26(3 Pt 2):458-461.

40. Saxena VN, Dogra J. Long-term use of penicillin for the treatment of chronic plaque psoriasis. Eur J Dermatol. 2005;15(5):359-362.

41. Komine M, Tamaki K. An open trial of oral macrolide treatment for psoriasis vulgaris. J Dermatol. 2000;27(8):508-512.

42. Polat M, Lenk N, Yalcin B, et al. Efficacy of erythromycin for psoriasis vulgaris. Clin Exp Dermatol. 2007;32(3):295-297.

43. Saxena VN, Dogra J. Long-term oral azithromycin in chronic plaque psoriasis: a controlled trial. Eur J Dermatol. 2010;20(3):329-333.

44. Fitoussi F, Cohen R, Brami G, et al. Molecular DNA analysis for differentiation of persistence or relapse from recurrence in treatment failure of Streptococcus pyogenes pharyngitis. Eur J Clin Microbiol Infect Dis. 1997;16(3):233-237.
Psoriasis: Targets and Therapy

\section{Publish your work in this journal}

Psoriasis: Targets and Therapy is international, peer-reviewed, open access journal focusing on psoriasis, nail psoriasis, psoriatic arthritis and related conditions, identification of therapeutic targets and the optimal use of integrated treatment interventions to achieve improved outcomes

\section{Dovepress}

and quality of life. Visit http://www.dovepress.com/testimonials.php to read real quotes from published authors. 